\title{
Potential effects of storm-water run-off on assemblages of mobile invertebrates
}

\author{
Giulia Ghedini*, Judith C. Klein, Ross A. Coleman \\ Centre for Research on Ecological Impacts of Coastal Cities, School of Biological Sciences, \\ Marine Ecology Laboratories (A11), The University of Sydney, New South Wales 2006, Australia
}

\begin{abstract}
Storm-water run-off is an important source of contamination and cause of water quality degradation in urbanised coastal areas. Although laboratory tests show that run-off is toxic for some organisms, its effects in the field remain uncertain. We investigated the effects of run-off on assemblages of mobile invertebrates within kelp beds in Sydney Harbour, Australia. We first tested patterns of differences in assemblages that are (1) directly associated with kelp holdfasts and those that are (2) developing on artificial units of habitat (AUHs) between locations with and without storm-water drains. We then transplanted assemblages on AUHs from locations without to locations with storm-water drains, predicting that assemblages would (1) change from those in the original location and (2) become more similar to those in the receiving location. Despite the initial pattern of differences in assemblages on AUHs, no clear effects of run-off were observed in the transplantation experiment. While transplanted assemblages changed in one location, no differences were detected in a second location. In a third location, there were experimental artefacts in the assemblage responses to transplantation. Total abundance (except for 1 location) and number of taxa did not change. Our results show the challenges of detecting potential impacts of disturbances in the field. First, manipulative experiments are necessary since the existence of patterns of differences can easily be observed, but does not necessarily indicate a causal relationship. Second, appropriate procedural controls are required as the experimental techniques can cause stress on organisms or can elicit different responses from them as a result of spatial variability.
\end{abstract}

KEY WORDS: Disturbance · Rainfall - Transplantation · Artificial units of habitat $\cdot$ Kelp bed

\section{INTRODUCTION}

Coastal areas are experiencing increasing levels of anthropogenic pressure as a consequence of urbanisation and exploitation of resources (Pressey et al. 2007). Human activities often alter habitats or ecological processes by modifying environmental conditions. Decreased water quality appears to be one of the main factors contributing to the degradation and loss of important biotic near-shore habitats, such as kelp beds and coral reefs (Benedetti-Cecchi et al. 2001, Bellwood et al. 2004). Over the past few decades, coastal run-off has steeply increased, becoming a primary cause of degradation of water quality (Gorgula \& Connell 2004, Birch \& Rochford
2010). In urbanised areas, storm-water run-off may contain a variety of contaminants, such as polycyclic aromatic hydrocarbons (PAHs), polychlorinated biphenyls (PCBs), metals, pesticides, bacteria, sewage from sewer overflows, oil and grease (Aryal et al. 2010). Run-off also discharges nutrients and sediments which can directly or indirectly affect habitatforming organisms and associated assemblages (Airoldi 2003, Gorman et al. 2009). Moreover, close to the outfalls, the input of fresh-water can reduce salinity for up to $4 \mathrm{~d}$ following a rainfall event (Roberts et al. 2007), with potential deleterious effects on marine organisms. As urbanisation along coastal areas increases and more intense and frequent rainfall events are expected in the next 
decades, relevant ecological information on the effects of storm-water run-off is essential for successful management and conservation of critical marine habitats.

A wide range of laboratory tests and a few in situ bioassays have established that exposure to stormwater effluent has lethal or sublethal effects on several species of aquatic organisms (Skinner et al. 1999, Carr et al. 2000, Bay et al. 2003, Schiff et al. 2003). To date, the ecological effects of storm-water run-off in natural systems remain uncertain. Although negative effects of run-off have been found on invertebrate assemblages in fresh-water systems (Pedersen \& Perkins 1986, Graves et al. 1998), only weak biological effects have been observed in marine and estuarine systems (Maxon et al. 1997, Nipper et al. 1998, Morrisey et al. 2003). Moreover, our current fieldbased knowledge is limited not only because few field studies have been done, particularly in marine systems, but, more importantly, because almost all of these studies have only involved mensurative tests (sensu Hurlbert 1984). Previous field studies qualitatively compared invertebrate assemblages between locations receiving storm-water run-off and putative control locations, often using only 1 or 2 replicate locations (Pedersen \& Perkins 1986, Morrisey et al. 2003). Such mensurative studies permit the detection of patterns of differences between control and 'impacted' places, which is the first step of any ecological study on a possible impact. However, mensurative studies are unable to provide causal relationships between patterns of differences among assemblages and the presence of the disturbance (i.e. storm-water run-off), particularly when they suffer from limited spatial or temporal replication (Underwood 1989, Mayer-Pinto et al. 2010). Several of these studies also tried to establish a quantitative correlation between observed differences in attributes of assemblages and concentration of contaminants from storm-water run-off (Maxon et al. 1997, Nipper et al. 1998, Morrisey et al. 2003). This correlation must exist if the run-off causes the differences in assemblages, but the existence of the correlation does not demonstrate that contamination by run-off causes the patterns of differences. Any other variable that differs among locations and that influences assemblages and the distribution of contaminants could also cause the observed correlation. In contrast to most studies, Roberts et al. (2007) sampled algalassociated assemblages multiple times before and after storm-water discharges in multiple locations with and without storm-water drains using an MBACI design (Underwood 1994). Although their sampling design increased the power of detecting potential impacts of run-off, it was difficult to link storm-water effects to changes in biota. There was a decrease in the abundance of a few taxa in locations with storm-water drains for up to $4 \mathrm{~d}$ following rainfall, but there was also a general decrease in the abundance of organisms in all locations, suggesting an effect of the rainfall itself. Subsequently, Roberts et al. (2008a) simulated storm-water pulses in the field and in the laboratory controlling for the variability of run-off. Their small-scale field experiment showed that a few taxa of algal-associated mobile invertebrates (amphipods and gastropods) decreased in abundance as a consequence of fresh-water flows and that the response was not different when metals were added to fresh-water. Contrary to the findings of most laboratory studies, the in vitro experiment of Roberts et al. (2008a) indicated that the decreased abundance of organisms was a result of behavioural avoidance rather than mortality. Their results suggest that storm-water pulses may have shortterm negative effects on the abundance of algalassociated invertebrates. However, for logistical reasons, the field experiments for this study (Roberts et al. 2008a) were limited in space and time (samples were taken within $30 \mathrm{~cm}$ of the outfall after $5 \mathrm{~min}$ of exposure), and results may thus not be representative of the response of organisms to most naturally occurring storm-water discharges.

Our aim was to test, for the first time, the existence of a causal relationship between run-off and differences in assemblages through a field-based manipulative experiment, using real storm-water discharges. We investigated the effects of storm-water run-off on assemblages of mobile invertebrates within beds of the kelp Ecklonia radiata (C. Agardh) J. Agardh in Sydney Harbour, NSW, Australia. Kelps are commonly found in Sydney Harbour and are often located close to storm-water outfalls. Hence, kelp beds represent an optimal study system to test the effects of run-off on associated assemblages. Invertebrate assemblages are often used as putative ecological indicators as they respond rapidly to changes in the environment and are composed of many species from several taxa, with a variety of life histories, reproductive strategies and feeding habits (Chapman et al. 1995, Morrisey et al. 2003, Courtenay et al. 2005). Assemblages associated with kelp holdfasts have been previously used in ecological studies assessing the effects of disturbances (e.g. sewage, oil spill) on hard bottom substrata (Smith \& Simpson 1992, 1995, Smith 1996a). However, holdfast-associated assemblages vary at small spatial 
scales due to variations in habitat characteristics (Smith 1996b, Smith et al. 1996, Anderson et al. 2005) and ecological history (Goodsell \& Connell 2005). This natural variability may prevent or make more difficult the detection of the effects of disturbances, particularly when the latter are small scale (Smith 1994). Variability can, however, be reduced through the use of artificial units of habitat (AUHs), which provide standard sampling units (e.g. volume, surface area, complexity) where assemblages of equal age and with no previous ecological history could develop (Gee \& Warwick 1996). In our study, AUHs also allowed us to unconfound possible indirect effects that storm-water run-off may have on assemblages mediated by the kelp (Marzinelli et al. 2009).

First, we sampled invertebrate assemblages that were (1) directly associated with kelp holdfasts and those that were (2) on AUHs (namely pot scourers) deployed within kelp beds to test for the existence of patterns which would validate an assemblage level response to run-off. Assemblages were sampled within $4 \mathrm{~d}$ of a rainfall event ( $>30 \mathrm{~mm}$ in total) as the abundance of organisms in algal-associated assemblages appears to be reduced during this period of time (Roberts et al. 2007). Second, we transplanted assemblages on AUHs from locations without stormwater drains to locations with storm-water drains. We predicted that transplanted assemblages would (1) change from those in the original location (i.e. without storm-water drain) and (2) become less different from those in the receiving location (i.e. with stormwater drain), when sampled within $4 \mathrm{~d}$ following a rainfall event occurring at least $3 \mathrm{wk}$ after transplantation. Transplanting assemblages from control to putatively impacted locations allowed us to test specific hypotheses on the effects of storm-water run-off on assemblages (i.e. changes in total abundance of organisms, number of species, structure and composition) and to separate these effects from those associated with local contingency (Chapman 1986).

\section{MATERIALS AND METHODS}

\section{Study locations}

The 2 studies were done in Sydney Harbour

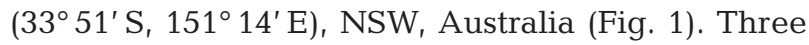
locations with storm-water drains and 3 others without drains were chosen as random representatives of potentially impacted and control sites. Study locations were standardised as much as possible to reduce natural variability of assemblages (Smith et

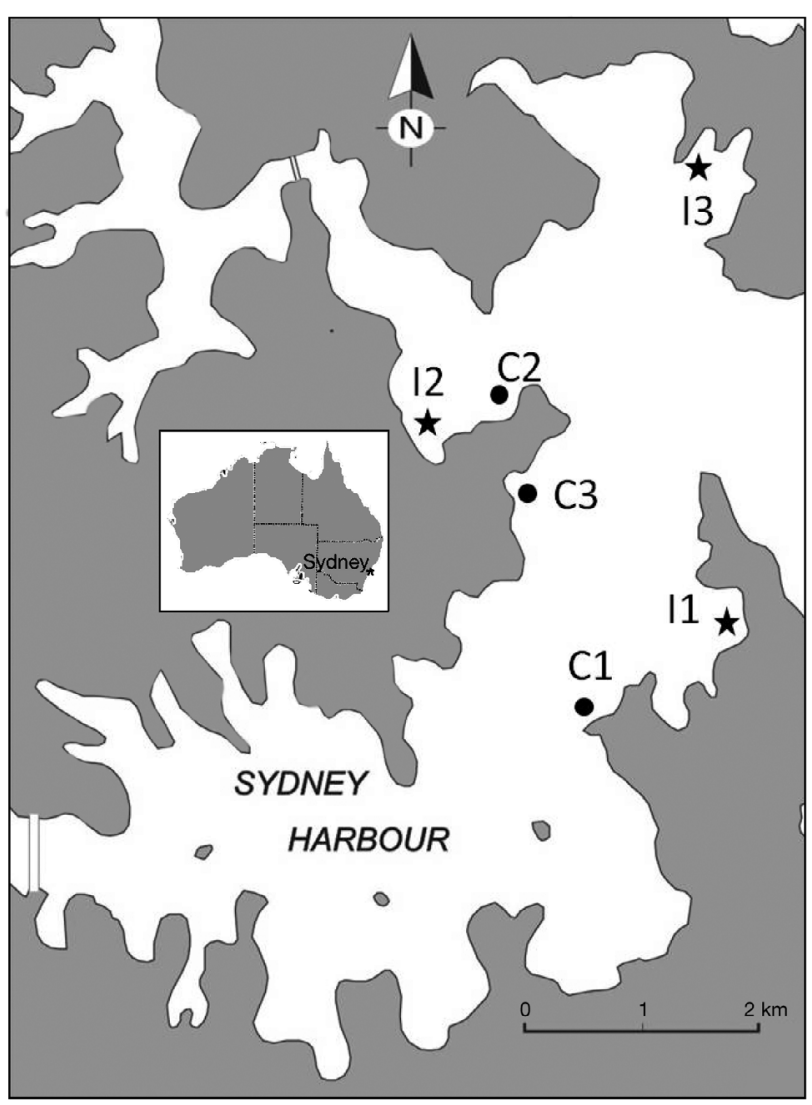

Fig. 1. Sydney Harbour, NSW, Australia (inset). Potentially impacted locations with storm-water drains $(\star)$ : I1 = Watson Bay, I2 = Balmoral Beach, I3 = Little Manly Cove. Control locations without storm-water drains $(\bullet)$ : C1 = Shark Bay, C2 = Cobblers Beach, C3 = Obelisk Beach

al. 1996). Thus, all of them were shallow rocky reefs (1 to $4 \mathrm{~m}$ below MLW) with beds of the kelp Ecklonia radiata, located in separate embayments, and exposure to wave action was similar. The density of kelp influences the associated assemblages and their response to disturbances (Goodsell et al. 2004, Goodsell \& Connell 2005). Therefore, the E. radiata canopy of the locations chosen was either monospecific sensu Goodsell et al. 2004 (i.e. $>80 \%$ of $1 \mathrm{~m}^{2}$ was covered by $E$. radiata) or clumped ( $>4$ ind. stand together) as these have comparable composition of associated assemblages and relative number of species (Goodsell et al. 2004). Watsons Bay (I1), Balmoral Beach (I2), and Little Manly Cove (I3) with stormwater drains $(\sim 0.75 \mathrm{~cm} \varnothing)$ discharging in front of and within $30 \mathrm{~m}$ of kelp beds were chosen as potentially impacted locations as they are subject to contamination by storm-water run-off, and the NSW Government issues advice discouraging swimming in these areas for up to $3 \mathrm{~d}$ following rainfall events (Anon 2010). The outfalls of these locations drain predomi- 
nantly highly urbanised, residential catchments. The run-off volumes discharged at each of the potentially impacted locations during the rainfall events prior to our samplings were estimated (Table 1) using the impervious surface area of the relative subcatchment and the average daily rainfall intensity (Lee et al. 2011; www.bom.gov.au/climate/data). Shark Bay (C1) was chosen as a control because contamination by run-off appears to be minimal here as there are no swimming restrictions following rainfall events (Anon 2010). The other 2 sites (Cobblers Beach - C2, Obelisk Beach - C3) have similar characteristics as C1. Hence, all control locations were (1) at a minimum distance of $300 \mathrm{~m}$ from any visible storm-water drain as properties of water quality (i.e. salinity and turbidity) at this minimum distance showed different temporal patterns of changes following rainfall compared to those in locations with storm-water drains (Roberts et al. 2007); and (2) surrounded by low density residential/park land areas, which a have a lower impervious surface area than highly urbanised areas (Lee et al. 2011).

Table 1. Rainfall in Sydney Harbour. Observations (mm) for May and June 2010 as recorded by the Australian Government Bureau of Meteorology at Dover Heights station (Stn no. $066209 ; 33.87^{\circ} \mathrm{S}, 151.28^{\circ} \mathrm{E}$; www.bom.gov.au/climate/ data) and estimates of volumes of run-off $\left(\mathrm{m}^{3}\right)$ discharged at each of the locations with storm-water drains (I1, I2, I3). Volumes of run-off at each potentially impacted site were estimated using the impervious surface area of the relative subcatchment and the average daily rainfall intensity (Lee et al. 2011). Only days of relevant rainfall events are given. Sampling dates are bold

\begin{tabular}{|cccccc|}
\hline \multicolumn{2}{|l}{$\begin{array}{l}\text { May/June } \\
2010\end{array}$} & Rain & \multicolumn{3}{c|}{ Run-off volume $\left(\mathrm{m}^{3}\right)$} \\
& & $(\mathrm{mm})$ & $\mathrm{I} 1$ & $\mathrm{I} 2$ & $\mathrm{I}$ \\
\hline \multirow{6}{*}{ May } & 22 & 34.8 & 2426 & 5697 & 4228 \\
& 23 & 28.2 & 1966 & 4616 & 3426 \\
& 24 & 6.6 & 460 & 1080 & 802 \\
25 & 0.6 & 42 & 98 & 73 \\
26 & 16.8 & 1171 & 2750 & 2041 \\
& 27 & 24.0 & 1673 & 3929 & 2916 \\
$\mathbf{2 8}$ & 1.0 & 70 & 164 & 121 \\
& 29 & 4.2 & 293 & 688 & 510 \\
30 & 3.4 & 237 & 557 & 413 \\
31 & 5.6 & 390 & 917 & 680 \\
June & 1 & 5.2 & 363 & 851 & 632 \\
$\mathbf{2}$ & 1.8 & & & \\
21 & 11.2 & 781 & 1833 & 1361 \\
23 & 5.4 & 376 & 884 & 656 \\
24 & 37.2 & 2593 & 6089 & 4519 \\
25 & 0.2 & 14 & 33 & 24 \\
26 & 0.4 & 28 & 65 & 49 \\
$\mathbf{2 8}$ & 0 & & & \\
\hline
\end{tabular}

\section{Patterns of differences in assemblages}

On 28 May 2010, 5 replicate holdfasts were haphazardly collected within kelp beds at 2 control and 2 potentially impacted locations. Each holdfast was collected by cutting off the stipe at $\sim 5 \mathrm{~cm}$ above the base of the alga and gently removing it from the substratum using a knife. Holdfasts were immediately placed in individual plastic bags which were then sealed with rubber bands.

The AUHs used in this study were nylon-mesh pot scourers of $\sim 10 \mathrm{~cm}$ diameter and $3 \mathrm{~cm}$ thickness (Sifa). In each of the 3 control and 3 potentially impacted locations, 4 replicate pot scourers were deployed within kelp beds for $6 \mathrm{wk}$ (21 April to 2 June 2010) to allow colonisation by organisms (Edgar \& Klumpp 2003, Hauser et al. 2006, Underwood \& Chapman 2006). Pot scourers were individually attached to the holdfasts of kelp plants that were haphazardly chosen within the beds. As the orientation and position of AUHs may influence the development of assemblages (Glasby \& Connell 2001), all pot scourers were suspended at a distance of $\sim 5 \mathrm{~cm}$ from the holdfast and 5-10 $\mathrm{cm}$ above the substratum. After the period of deployment, all pot scourers were collected and placed in plastic bags, which were then sealed with rubber bands.

Samples of either holdfasts or pot scourers were collected after a rainfall event (Table 1). On the day of sampling, holdfasts or pot scourers were collected between 10:00 and 14:00 h, as it is known that the abundance of some algal-associated taxa (e.g. amphipods) can vary during the day (Jorgensen \& Christie 2003). Holdfasts and pot scourers were taken to the laboratory within 5 h (Chapman \& Underwood 2005, Chapman et al. 2008). Holdfast samples were kept at $4^{\circ} \mathrm{C}$ and sorted within $1 \mathrm{wk}$ from collection. Pot scourers were preserved in a $7 \%$ formalin solution buffered with seawater. All samples were rinsed onto a $500 \mu \mathrm{m}$ sieve to collect macrofauna. Each holdfast was dissected to collect the animals living within the numerous branches of the holdfast and the volume of the holdfast was assessed using the water immersion method (Sheppard et al. 1980). Each pot scourer was unravelled and carefully washed onto a sieve to remove all organisms. Macrofauna were then sorted and counted. Organisms were identified to a degree of taxonomic resolution that varied from taxa to morphospecies as it has been demonstrated that sorting to different taxonomic resolutions can show the same patterns as sorting to species level (Chapman 1998).

Prior to analyses, the abundance of organisms and the number of taxa of assemblages on holdfasts were 
standardised to a $100 \mathrm{ml}$ volume because these 2 variables are related to the volume of the holdfast (Smith et al. 1996, Anderson et al. 2005). This standardisation may be problematic under speciose conditions, but it was used as a conservative way of accounting for variation in volumes. If the relationship between volume and species number is consistent across locations, it is possible to use volume as a covariate in an analysis of covariance (ANCOVA) (Smith et al. 1996).

Univariate ANOVA was used to test the null hypothesis of no difference in the total abundance of organisms and number of taxa of assemblages, on either holdfasts or pot scourers, between control and potentially impacted locations. Factors were 'Drain' (2 fixed levels, control vs. impacted) and 'Location' ( 2 and 3 random levels for holdfasts and pot scourers respectively, nested within 'Drain'). Prior to all ANOVAs, the assumption of homoscedasticity was tested using Cochran's $(C)$ test. Where necessary, data were transformed to stabilise variances (Underwood 1997). Where significant differences were found ( $\mathrm{p} \leq$ 0.05), post-hoc Student-Newman-Keuls (SNK) comparisons of means were done. All ANOVAs were done using GMAV 5 for Windows (EICC, The University of Sydney). The same analytical structure was used in permutational multivariate analysis of variance (PERMANOVA) (Anderson 2001) testing the null hypothesis of no difference in the structure and composition of assemblages between control and potentially impacted locations. In order to reduce the contribution of quantitatively dominant taxa, data on abundance were square-root $(x+1)$ transformed prior to the construction of Bray-Curtis similarity matrices. Where significant differences were found, pair-wise tests were done to investigate how levels of the factor 'Drain' differed. Non-metric multidimensional scaling (nMDS) plots were constructed from the Bray-Curtis matrices to graphically represent the data. All multivariate analyses were done using PRIMER-E v6 software package (Primer-E).

\section{Experimental transplantation of assemblages}

Invertebrate assemblages which colonised pot scourers were transplanted from the 3 control sites to the 3 potentially impacted locations in a 1-way transplantation experiment. The limited number of kelp at location I1 prevented us from doing a reciprocal transplantation experiment, i.e. moving assemblages from control to potentially impacted locations and vice versa. Appropriate procedural controls were included to unconfound potential experimental artefacts from the effects of storm-water run-off on assemblages (Chapman 1986). Hence, in each control location, assemblages were assigned to 1 of 4 different treatments: undisturbed assemblages (Uc), which were not touched until the final collection; disturbed assemblages (D), which were picked up and replaced in the same position to control for the effects of handling assemblages; translocated assemblages (TL), which were moved from a control to another control location to account for the effects of changing local environmental conditions; transplanted assemblages (TP), which were moved from a control to a potentially impacted location $(\mathrm{C} 1 \rightarrow \mathrm{I} 1$; $\mathrm{C} 2 \rightarrow \mathrm{I} 2$; C3 $\rightarrow$ I3) to test for the effects of storm-water run-off. At the start of the experiment, each impacted location had only 1 treatment, i.e. undisturbed assemblages (Ui), before receiving TP assemblages from one of the control locations.

In each location, 4 replicate pot scourers were deployed for each treatment for 6 wk (21 April to 2 June 2010) to allow colonisation by organisms,. Then D, TL and TP pot scourers were manipulated accordingly. The experimental manipulation lasted $<2 \mathrm{~h}$ for each pot scourer and, during this time, plastic bags containing the samples were immersed in a tank filled with seawater. Pot scourers were left in the field for 3 more weeks (2 to 28 June 2010) and collected $4 \mathrm{~d}$ after a rainfall event (Table 1). Three weeks were considered sufficient for TL and TP assemblages to change in response to the new local environmental conditions as mobile macrofauna associated with algae are highly mobile and respond rapidly to perturbations in the environment (Edgar 1991a, Martin-Smith 1994). Procedures of deployment, collection and sorting were as described above.

A mixed model with 2 factors, Treatment (4 fixed levels: Uc, D, TL and TP) and Location (3 random levels, orthogonal to Treatment), was used to test (analysis 1) whether transplanted assemblages (TP) changed compared to the undisturbed assemblages in the original location (Uc) and whether there was an effect of the experimental manipulation itself on assemblages (D, TL). In analysis 1, TL and TP assemblages were considered according to the location of origin. ANOVAs were used to test the null hypothesis of no changes in the total abundance of organisms and in the number of taxa, while PERMANOVA was used to test the null hypothesis of no changes in the structure and composition of assemblages. Prior to multivariate and univariate analyses, data were 
treated as described above. Where significant differences ( $p \leq 0.05$ ) were found, post-hoc SNK comparisons of means and pair-wise tests were done for ANOVAs and PERMANOVA respectively. If TP assemblages changed compared to control assemblages (Uc, D, TL), we then tested (analysis 2) whether TP assemblages became similar to the assemblages in the receiving location (Ui). In analysis 2, TP assemblages were considered according to the location after manipulation and the factor Treatment had 2 fixed levels (TP, Ui). Data on abundance of all treatments for each 'pair' of control and potentially impacted locations (according to the transplantation) were graphically represented in nMDS plots based on the Bray-Curtis similarity matrix.

\section{RESULTS}

The rainfall events prior to our sampling were substantial, resulting in flows between 42 and $4616 \mathrm{~m}^{3}$ for the rainfall event on 22 May to 1 June 2010 (for the investigation on the patterns of differences in assemblages) and between 14 and $6089 \mathrm{~m}^{3}$ for
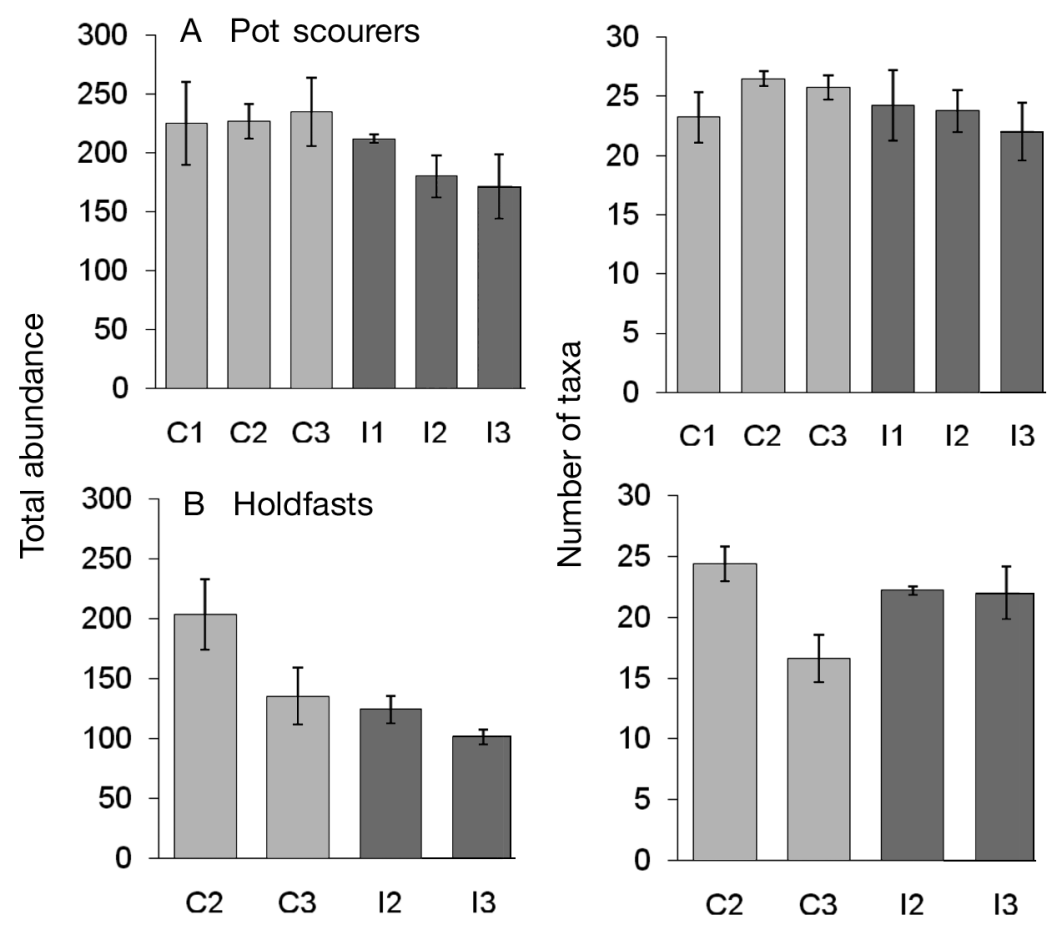

Fig. 2. Total abundance of organisms and number of taxa (mean \pm SE) of assemblages on (A) pot scourers $(n=4)$ from 3 control (light bars) and 3 impacted (dark bars) locations, and $(\mathrm{B})$ holdfasts $(\mathrm{n}=5)$ from 2 control (light bars) and 2 impacted (dark bars) locations. C1, C2, C3: control locations without storm-water drains; I1, I2, I3: potentially impacted locations with storm-water drains. Volume (mean $\pm \mathrm{SE}, \mathrm{ml} ; \mathrm{n}=5$ ) of holdfasts for each sampled location: $\mathrm{C} 2=170 \pm 21.5 ; \mathrm{C} 3=110 \pm 23.2 ; \mathrm{I} 2=275 \pm 55.9 ; \mathrm{I} 3=155 \pm 25.5$ the rainfall event on 21 to 26 June 2010 (for the experimental transplantation of assemblages) at each of the different outfalls used for the experiments (Table 1).

\section{Patterns of differences in assemblages}

The total abundance of organisms on pot scourers was greater in control than in potentially impacted locations (Fig. 2, Table 2). No differences were found in the total abundance of organisms on holdfasts and in the number of taxa for either holdfasts or pot scourers (Fig. 2, Table 2). We could not use an ANCOVA to assess the contribution of holdfast volume to the variation in assemblage properties as the important assumption of homogeneity of slopes (Sokal \& Rohlf 1995) was not satisfied (pseudo $F_{2,12}=4.064, \mathrm{p}<$ $0.05)$. The volume (mean $\pm \mathrm{SE}$ ) of holdfasts for each sampled location is provided in Table 2 and Fig. 2.

Although the stresses of the nMDS plots were relatively high (0.17 and 0.19 for holdfasts and pot scourers respectively), assemblages from control and impacted locations appeared to plot separately

(Fig. 3). PERMANOVA, however, did not show any significant difference in the structure and composition of assemblages between control and impacted locations, on either pot scourers (pseudo $F_{1,4}=1,19, \mathrm{p}>0.40$ ) or holdfasts (pseudo $F_{1,2}=1,17, \mathrm{p}>0.66$ ). Hence, we retained the null hypothesis of no difference. Assemblages were significantly different among locations, but this was not investigated further as there were no hypotheses for locations.

\section{Experimental transplantation of assemblages}

The experimental treatments had different effects on the structure and composition of assemblages in the various locations (analysis 1; Table 3). Pair-wise tests showed that, in 2 cases, transplanted assemblages (TP) changed compared to undisturbed assemblages (Uc) in the original location. In location C1, however, there was a clear manipulation effect as disturbed (D) and translocated (TL) assemblages were significantly different from each other 
Table 2. ANOVA for differences in the total abundance of organisms and number of taxa of assemblages in control (without storm-water drains) and potentially impacted (with storm-water drains) locations. Assemblages on pot scourers ( $\mathrm{n}=4$ ): Drain had 2 fixed levels (control vs. potentially impacted), Location had 3 random levels, nested within Drain. Assemblages on holdfasts $(\mathrm{n}=5)$ : Drain had 2 fixed levels (control vs. potentially impacted), Location had 2 random levels, nested within Drain. Volume $(\mathrm{ml})$ of holdfasts (mean $\pm \mathrm{SE}_{;} \mathrm{n}=5$ ) for each control $(\mathrm{C})$ and potentially impacted (I) location: $\mathrm{C} 2=170 \pm 21.5 ; \mathrm{C} 3=110 \pm$ 23.2; I $=275 \pm 55.9 ;$ I $3=155 \pm 25.5$. SNK: Student-Newman-Keuls test. p: terms significant at $\alpha=0.05$ are in bold. Pooling was used according to Underwood (1997)

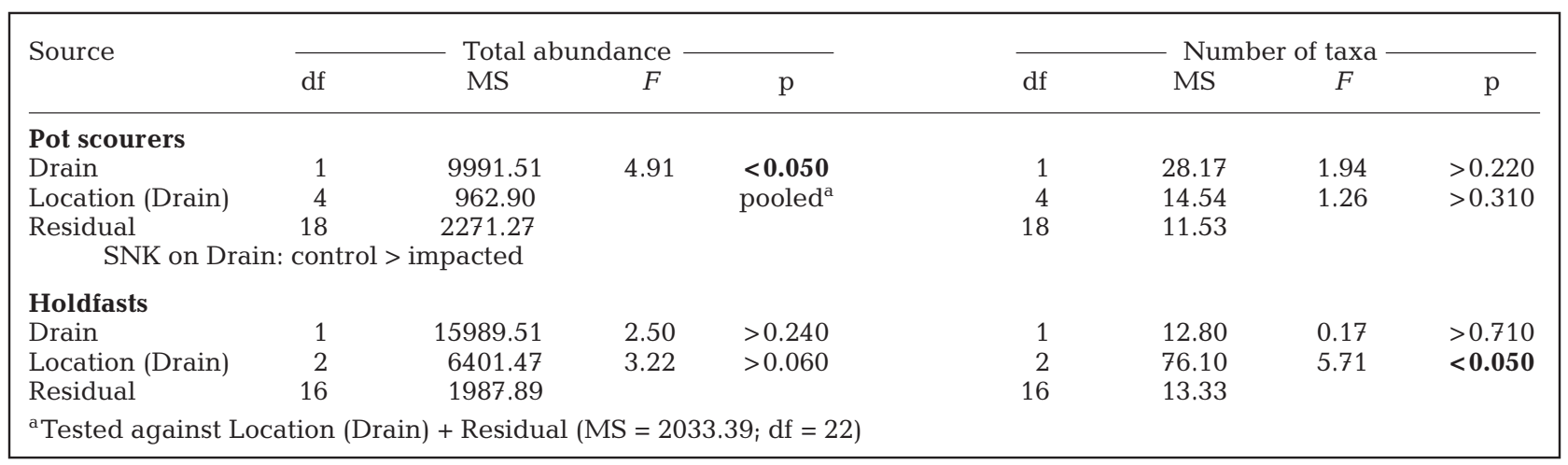

and from either Uc or TP assemblages. In location C3, TP assemblages, although different from Uc assemblages, were not significantly different from the other control assemblages (D and TL), which in turn were not significantly different from Uc assemblages. In the third location (C2), no significant differences among any of the treatments were detected. In all 3 potentially impacted locations, TP assemblages were significantly different from undisturbed assemblages (Ui) in the receiving location (analysis 2; Table 3). In the 3 nMDS plots (1 plot for each 'pair' of control and impacted locations), the treatments plots were consistent with patterns from the PERMANOVA results for each location (Fig. 4).

In 1 of the control locations (C1), the experimental manipulation also had effects on the total abundance of organisms as this was significantly lower in manipulated (D, TL and TP) than in undisturbed (Uc) assemblages (Fig. 5A, Table 4). No effects either of the transplantation (i.e. run-off) or of the experimental manipulation were observed on the total abundance of organisms in the other 2 locations
(Fig. 5B,C, Table 4) and on the number of taxa in all 3 locations (Table 4). Since TP assemblages did not change in terms of total abundance of organisms (except for 1 location where changes were due to a manipulation effect) and number of taxa, we did not proceed with analysis 2 (TP vs. Ui) for these variables.

\section{DISCUSSION}

Overall, as in some previous studies (Maxon et al. 1997, Nipper et al. 1998, Roberts et al. 2007), we did not find evidence to support the model that stormwater run-off has strong, clear negative effects on invertebrate assemblages as suggested by laboratory tests (Skinner et al. 1999, Carr et al. 2000, Bay et al. 2003, Schiff et al. 2003). Our mensurative sampling using AUHs revealed a pattern of difference in assemblages between locations receiving and those not receiving storm-water run-off. Although this preliminary result would suggest a negative effect of
Fig. 3. Non-metric multidimensional scaling (nMDS) plots of assemblages on (A) pot scourers $(n=4)$ from 3 control and 3 potentially impacted locations, and (B) holdfasts ( $\mathrm{n}=5$ ) from 2 control and 2 potentially impacted locations. Assemblages from control locations (without storm-water drains): () $\mathrm{C} 1 ;(\Delta) \mathrm{C} 2 ;(\mathrm{O}) \mathrm{C} 3$. Assemblages from potentially impacted locations (with storm-

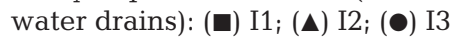
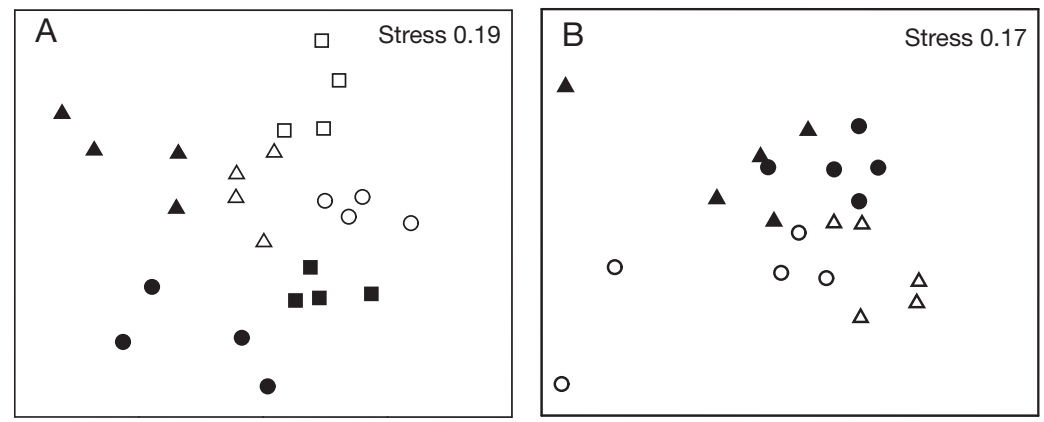
Table 3. Permutational multivariate analysis of variance (PERMANOVA) on assemblages on pot scourers $(n=4)$ subsequent to manipulation. Analysis 1 tested whether transplanted assemblages changed compared to assemblages in control locations (without storm-water drains). Treatment had 4 fixed levels: assemblages left undisturbed in control locations (Uc), experimentally disturbed in control locations (D), moved within control locations (TL), or transplanted to potentially impacted locations (TP). Location had 3 random levels (C1, C2, C3), orthogonal to Treatment. Analysis 2 tested whether transplanted assemblages became similar to assemblages in the potentially impacted locations (with storm-water drains). Treatment had 2 fixed levels: assemblages left undisturbed in potentially impacted locations (Ui), or received from control locations (TP). Location had 3 random levels (I1, I2, I3), orthogonal to Treatment. Terms significant at $\alpha=0.05$ are in bold

\begin{tabular}{|c|c|c|c|c|c|c|}
\hline \multicolumn{7}{|c|}{ Analysis 1: Uc, D, TL, TP } \\
\hline \multicolumn{2}{|c|}{ Source } & df & MS & \multicolumn{2}{|c|}{ Pseudo $F$} & $\mathrm{p}(\mathrm{perm})$ \\
\hline \multicolumn{2}{|l|}{ Treatment T } & 3 & 1051.7 & \multicolumn{2}{|c|}{1.50} & 0.069 \\
\hline \multicolumn{2}{|l|}{ Location Lo } & 2 & 3543.4 & \multicolumn{2}{|c|}{8.34} & $<0.001$ \\
\hline \multicolumn{2}{|l|}{$\mathrm{T} \times \mathrm{Lo}$} & 6 & 699.16 & \multicolumn{2}{|c|}{1.65} & $<0.001$ \\
\hline \multicolumn{2}{|l|}{ Residual } & 36 & 424.65 & & & \\
\hline \multicolumn{7}{|c|}{ Pair-wise tests on $T \times$ Lo for pairs of levels of $T$} \\
\hline & \multicolumn{2}{|c|}{$\begin{array}{ll}- & \mathrm{C} 1- \\
t & \mathrm{p}(\text { perm })\end{array}$} & $\bar{t}$ & $\mathrm{p}($ perm $)$ & \multicolumn{2}{|c|}{$\begin{array}{l}-\mathrm{C} 3- \\
\quad \mathrm{p}(\text { perm })\end{array}$} \\
\hline $\mathrm{C}, \mathrm{D}$ & 1.61 & 0.03 & 1.15 & 0.15 & 1.37 & 0.066 \\
\hline $\mathrm{C}, \mathrm{TL}$ & 1.82 & 0.03 & 1.10 & 0.31 & 1.27 & 0.06 \\
\hline C, TP & 2.15 & 0.03 & 0.91 & 0.69 & 1.49 & 0.03 \\
\hline $\mathrm{D}, \mathrm{TL}$ & 1.70 & 0.03 & 1.27 & 0.06 & 1.15 & 0.19 \\
\hline $\mathrm{D}, \mathrm{TP}$ & 1.66 & 0.03 & 1.12 & 0.26 & 1.35 & 0.09 \\
\hline TL, TP & 1.74 & 0.03 & 1.24 & 0.09 & 1.02 & 0.3 \\
\hline \multicolumn{7}{|c|}{ Analysis 2: TP, Ui } \\
\hline Source & & df & MS & \multicolumn{2}{|c|}{ Pseudo $F$} & $\mathrm{p}($ perm $)$ \\
\hline \multicolumn{2}{|l|}{ Treatment T } & 1 & 1254.8 & \multicolumn{2}{|c|}{1.09} & 0.366 \\
\hline \multicolumn{2}{|l|}{ Location Lo } & 2 & 2628.7 & \multicolumn{2}{|c|}{5.64} & $<0.001$ \\
\hline \multicolumn{2}{|l|}{$\mathrm{T} \times$ Lo } & 2 & 1148.9 & \multicolumn{2}{|c|}{2.46} & $<0.001$ \\
\hline \multicolumn{2}{|l|}{ Residual } & 18 & 466.42 & & & \\
\hline \multicolumn{7}{|c|}{ Pair-wise tests on $\mathrm{T} \times$ Lo for pairs of levels of $\mathrm{T}$} \\
\hline & 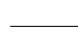 & $\mathrm{I} 1 \longrightarrow$ & 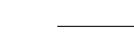 & $\mathrm{I} 2$ & 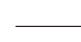 & $-\mathrm{I} 3$ \\
\hline & $t$ & $\mathrm{p}($ perm) & $t$ & $\mathrm{p}($ perm $)$ & $t$ & $\mathrm{p}($ perm $)$ \\
\hline $\mathrm{TP}, \mathrm{Ui}$ & 1.72 & 0.03 & 1.46 & 0.03 & 1.60 & 0.03 \\
\hline
\end{tabular}

run-off on assemblages, as supported by laboratory tests and a few previous field studies (Pedersen \& Perkins 1986, Graves et al. 1998, Morrisey et al. 2003), the existence of patterns of differences does not demonstrate that storm-water run-off caused the observed differences in assemblages. Unambiguous evidence of causal relationships can only be provided by manipulative experiments (Underwood 1989), such as the experimental transplantation of assemblages we have described. Contrary to our initial hypothesis, results from the experimental transplantation did not indicate clear effects of run-off on assemblages, either in terms of total abundance of organisms (except for 1 location, see below) or number of taxa. Overall, there were also no clear effects of run-off on the structure and composition of assemblages. In only 1 case out of 3 , observed changes in transplanted assemblages could be attributed to run-off and, even in this case, transplanted assemblages were not significantly different from disturbed and translocated assemblages, although they were significantly different from undisturbed assemblages. Interestingly, we consistently observed an effect of the experimental manipulation in 1 location; here, the procedures that we used to manipulate assemblages caused disturbance on organisms and 3 additional weeks of deployment after the manip-

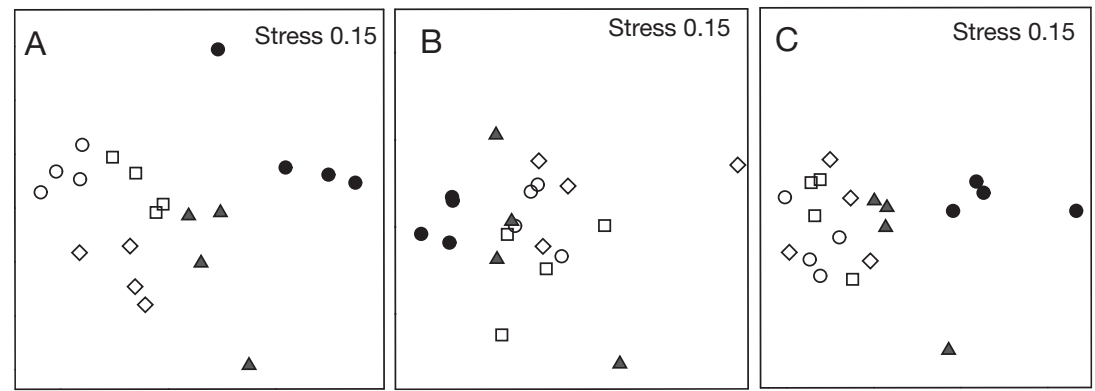

Fig. 4. Non-metric multidimensional scaling (nMDS) plots of assemblages $(\mathrm{n}=4)$ left undisturbed in control locations $(\mathrm{O})$, experimentally disturbed in control locations $(\square)$, moved within control locations $(\diamond)$, transplanted to potentially impacted locations $(\Delta)$ or left undisturbed in potentially impacted locations $(\bullet)$. (A) Control location C1 (without storm-water drain) and potentially impacted location I1 (with storm-water drain); (B) C2 and I2; (C) C3 and I3 
unexploited habitat for organisms. Assemblages developing on AUHs have no previous ecological history and are only influenced by recruitment, reproductive and other processes occurring during the period of deployment (Gee \& Warwick 1996, Underwood \& Chapman 2006). Thus, AUHs reduce the variability of assemblages, particularly at small spatial scales, i.e. tens of metres (Smith \& Rule 2002, Edgar \& Klumpp 2003). These characteristics of AUHs may explain why we observed a pattern of difference in assemblages on AUHs and not on holdfasts. The AUHs were colonised within 6 wk by a similar or greater abundance of organisms and by a similar number of taxa compared to those of assemblages on holdfasts. Assemblages on AUHs were dominated by amphipods and polychaetes (G. Ghedini et al. unpubl. data) as also reported for assemblages on holdfasts (Smith \& Simpson 1992, Smith 1994, 2000). Here, however, we would like to limit our comparison between the 2 habitats as they have very different structural characteristics (e.g. volume, surface area, complexity) whose effects on assemblages are often confounded and need to be addressed separately (Kostylev et al. 2005, Hauser et al. 2006, Matias et al. 2007). Despite increased standardisation of habitat characteristics, we observed spatial variability in assemblages on AUHs and in their response to disturbances (i.e. experimental manipulation and run-off). This confirms that assemblages developing on AUHs respond to local environmental conditions and, thus, can be useful tools for detecting effects of disturbances in the field (Edgar 1991b, Edgar \& Klumpp 2003, Gobin \& Warwick 2006).

The results obtained in this and in previous field studies (Maxon et al. 1997, Nipper et al. 1998, Morrisey et al. 2003, Roberts et al. 2007) contrast with the findings of laboratory and mesocosm studies, which suggest strong toxic effects of run-off on several species of marine and fresh-water invertebrates (Hatch \& Burton 1999, Skinner et al. 1999, Carr et al. 2000, Bay et al. 2003, Schiff et al. 2003, Grapentine et al. 2008). Laboratory tests are not always good predictors of the ecological effects of a disturbance (e.g. storm-water run-off) in natural systems. In the field, the response of organisms or the effects of the disturbance may be influenced by complex interactions between abiotic factors (e.g. temperature, $\mathrm{pH}$, contaminants) and biotic processes (e.g. predation, competition, reproduction) that are not represented in laboratory or mesocosm studies (Connell 1974, Johnston \& Keough 2003). The pulsed nature of storm-water run-off complicates the identification of its effects on assemblages in the field. As the occurrence, duration, amount and type of contaminants in run-off may vary substantially in space and time (Birch et al. 2010), the response of organisms to this disturbance may also vary spatially and temporally, as we have observed in our study. Although experiments with simulations of storm-water pulses allow control of the variability of the run-off and can be used to evaluate possible impacts at small spatial and temporal scales (Roberts et al. 2008a), they do not assess the effects of natural run-off events. Alternatively, these effects could be evaluated by measuring the evolution and the characteristics of real storm-water plumes (e.g. Washburn et al. 2003) and taking these variables into account when assessing the response of organisms.

The lack of detected changes in terms of altered abundance or composition of assemblages in response to storm-water run-off does not necessarily correspond to the absence of impacts. Individual organisms may be able to cope with the disturbance through complex physiological adaptations, which may have long-term ecological costs in terms of survival or reproduction (Underwood 1989). This would be likely in Sydney Harbour and in other densely populated estuaries or coastal areas that have high and widespread levels of contamination (Birch \& Rochford 2010). In these areas, the choice of appropriate control locations may be difficult and the presence of contaminants and other anthropogenic disturbances may result in constant stress on organisms. Therefore, run-off may have an additional, but subtle and very localised effects (Roberts et al. 2007). The effects of run-off may be stronger in areas with lower levels of background contamination, such as in South Australia where run-off has been linked to the loss of kelp beds (Gorman et al. 2009). Moreover, it remains important to test whether storm-water run-off has indirect negative effects (i.e. habitat-mediated) on assemblages associated with habitat-forming organisms. Kelp and other biogenic habitats can accumulate contaminants in their tissues (see Roberts et al. 2008b for a review) and possible indirect effects on associated assemblages need to be tested in a properly designed experiment (Marzinelli et al. 2009). As storm-water run-off remains a primary source of contamination and cause of water quality degradation, we suggest that it is necessary to clarify the conditions under which effects of run-off on assemblages are observed. To do so, it is fundamental that future studies (1) involve manipulative field experiments to demonstrate a cause-effect relationship, and (2) include appropriate procedural controls to avoid misinterpretation of results. 
Acknowledgements. The work was funded by the Centre for Research on Ecological Impacts of Coastal Cities and the School of Biological Sciences. J.C.K. was supported by a German Research Foundation fellowship (Deutsche Forschungsgemeinschaft, KL-2264/1-1). We thank A. Bugnot, F. Moreira, M. Mayer-Pinto, M. Day, E. Marzinelli, C. Fraser, R. Galaiduk, A. Brown and A. Afable for assisting in the field; G. Birch and S. Lee for help with the storm-water flow data; M. Mayer-Pinto and E. Marzinelli for comments on data analyses and on the manuscript.

\section{LITERATURE CITED}

Airoldi L (2003) The effects of sedimentation on rocky coast assemblages. Oceanogr Mar Biol Annu Rev 41:161-236

Anderson MJ (2001) A new method for non-parametric multivariate analysis of variance. Austral Ecol 26:32-46

Anderson MJ, Diebel CE, Blom WM, Landers TJ (2005) Consistency and variation in kelp holdfast assemblages: spatial patterns of biodiversity for the major phyla at different taxonomic resolutions. J Exp Mar Biol Ecol 320: $35-56$

Anon (2010) New South Wales state of the beaches 2009-2010. Department of Environment, Climate Change and Water NSW, Sydney, NSW

> Aryal R, Vigneswaran S, Kandasamy J, Naidu R (2010) Urban stormwater quality and treatment. Korean J Chem Eng 27:1343-1359

Bay S, Jones BH, Schiff K, Washburn L (2003) Water quality impacts of stormwater discharges to Santa Monica Bay. Mar Environ Res 56:205-223

Bellwood DR, Hughes TP, Folke C, Nystrom M (2004) Confronting the coral reef crisis. Nature 429:827-833

Benedetti-Cecchi L, Pannacciulli F, Bulleri F, Moschella PS, Airoldi L, Relini G, Cinelli F (2001) Predicting the consequences of anthropogenic disturbance: large-scale effects of loss of canopy algae on rocky shores. Mar Ecol Prog Ser 214:137-150

Birch GF, Rochford L (2010) Stormwater metal loading to a well-mixed/stratified estuary (Sydney estuary, Australia) and management implications. Environ Monit Assess 169:531-551

Birch GF, Cruickshank B, Davis B (2010) Modelling nutrient loads to Sydney estuary (Australia). Environ Monit Assess 167:333-348

Carr RS, Montagna PA, Biedenbach JM, Kalke R, Kennicutt MC, Hooten R, Cripe G (2000) Impact of storm-water outfalls on sediment quality in Corpus Christi Bay, Texas, USA. Environ Toxicol Chem 19:561-574

> Chapman MG (1986) Assessment of some controls in experimental transplants of intertidal gastropods. J Exp Mar Biol Ecol 103:181-202

Chapman MG (1998) Relationships between spatial patterns of benthic assemblages in a mangrove forest using different levels of taxonomic resolution. Mar Ecol Prog Ser 162:71-78

Chapman MG (1999) Assessment of variability in responses of intertidal periwinkles to experimental transplantations. J Exp Mar Biol Ecol 236:171-190

Chapman MG, Underwood AJ (2005) Biological monitoring of macrofauna in artificial units of habitat on intertidal rocky shores in Berowra Creek: report for Hornsby Council. Centre for Research on Ecological Impacts of Coastal Cities, Sydney
Chapman MG, Underwood AJ, Skilleter GA (1995) Variability at different spatial scales between a subtidal assemblage exposed to the discharge of sewage and two control assemblages. J Exp Mar Biol Ecol 189:103-122

> Chapman MG, Underwood AJ, Blockley D (2008) Effects of methods of deployment of artificial units of habitat on microgastropod colonisation. Mar Ecol Prog Ser 366: 49-57

Connell JH (1974) Ecology: field experiments in marine ecology. In: Mariscal RN (ed) Experimental marine biology. Academic Press, New York, NY, p 21-54

> Courtenay GC, Gladstone W, Schreider M (2005) Assessing the response of estuarine intertidal assemblages to urbanised catchment discharge. Environ Monit Assess 107:375-398

Edgar GJ (1991a) Artificial algae as habitats for mobile epifauna: factors affecting colonization in a Japanese Sargassum bed. Hydrobiologia 226:111-118

Edgar GJ (1991b) Distribution patterns of mobile epifauna associated with rope-fiber habitats within the Barthurst Harbour estuary, South-Western Tasmania. Estuar Coast Shelf Sci 33:589-604

> Edgar GJ, Klumpp DW (2003) Consistency over regional scales in assemblages of mobile epifauna associated with natural and artificial plants of different shape. Aquat Bot 75:275-291

> Gee JM, Warwick RM (1996) A study of global biodiversity patterns in the marine motile fauna of hard substrata. J Mar Biol Assoc UK 76:177-184

Glasby TM, Connell SD (2001) Orientation and position of substrata have large effects on epibiotic assemblages. Mar Ecol Prog Ser 214:127-135

Gobin JF, Warwick RM (2006) Geographical variation in species diversity: a comparison of marine polychaetes and nematodes. J Exp Mar Biol Ecol 330:234-244

> Goodsell PJ, Connell SD (2005) Historical configuration of habitat influences the effects of disturbance on mobile invertebrates. Mar Ecol Prog Ser 299:79-87

Goodsell PJ, Fowler-Walker MJ, Gillanders BM, Connell SD (2004) Variations in the configuration of algae in subtidal forests: implications for invertebrate assemblages. Austral Ecol 29:350-357

> Gorgula SK, Connell SD (2004) Expansive covers of turfforming algae on human-dominated coast: the relative effects of increasing nutrient and sediment loads. Mar Biol 145:613-619

> Gorman D, Russell BD, Connell SD (2009) Land-toseaconnectivity: linking human-derived terrestrial subsidies to subtidal habitat change on open rocky coasts. Ecol Appl 19:1114-1126

Grapentine L, Rochfort Q, Marsalek J (2008) Assessing urban stormwater toxicity: methodology evolution from point observations to longitudinal profiling. Water Sci Technol 57:1375-1381

> Graves GA, Strom DG, Robson BE (1998) Stormwater impact to the freshwater Savannas Preserve marsh, Florida, USA. Hydrobiologia 379:111-122

Hatch AC, Burton GA (1999) Sediment toxicity and stormwater runoff in a contaminated receiving system: consideration of different bioassays in the laboratory and in the field. Chemosphere 39:1001-1017

Hauser A, Attrill MJ, Cotton PA (2006) Effects of habitat complexity on the diversity and abundance of macrofauna colonising artificial kelp holdfasts. Mar Ecol Prog Ser 325:93-100 
Honkoop PJC, Bayne BL, Underwood AJ, Svensson S (2003) Appropriate experimental design for transplanting mussels (Mytilus sp.) in analyses of environmental stress: an example in Sydney Harbour (Australia). J Exp Mar Biol Ecol 297:253-268

Hurlbert SH (1984) Pseudoreplication and the design of ecological field experiments. Ecol Monogr 54:187-211

> Johnston EL, Keough MJ (2003) Competition modifies the response of organisms to toxic disturbance. Mar Ecol Prog Ser 251:15-26

Jorgensen NM, Christie H (2003) Diurnal, horizontal and vertical dispersal of kelp-associated fauna. Hydrobiologia 503:69-76

Kostylev VE, Erlandsson J, Ming MY, Williams GA (2005) The relative importance of habitat complexity and surface area in assessing biodiversity: fractal application on rocky shores. Ecol Complex 2:272-286

Lee SB, Birch GF, Lemckert C (2011) Field and modelling investigations of fresh-water plume behaviour in response to infrequent high-precipitation events, Sydney Estuary, Australia. Estuar Coast Shelf Sci 92:389-402

> Martin-Smith KM (1994) Short-term dynamics of tropical macroalgal epifauna: patterns and processes in recolonization of Sargassum fissifolium. Mar Ecol Prog Ser 110: $177-185$

Marzinelli EM, Zagal CJ, Chapman MG, Underwood AJ (2009) Do modified habitats have direct or indirect effects on epifauna? Ecology 90:2948-2955

- Matias MG, Underwood AJ, Coleman RA (2007) Interactions of components of habitats alter composition and variability of assemblages. J Anim Ecol 76:986-994

Maxon CL, Barnett AM, Diener DR (1997) Sediment contaminants and biological effects in southern California: use of a multivariate statistical approach to assess biological impact. Environ Toxicol Chem 16:775-784

- Mayer-Pinto M, Underwood AJ, Tolhurst T, Coleman RA (2010) Effects of metals on aquatic assemblages: What do we really know? J Exp Mar Biol Ecol 391:1-9

Morrisey DJ, Turner SJ, Mills GN, Williamson RB, Wise BE (2003) Factors affecting the distribution of benthic macrofauna in estuaries contaminated by urban run-off. Mar Environ Res 55:113-136

> Myers AA, Southgate T (1980) Artificial substrates as a means of monitoring rocky shore cryptofauna. J Mar Biol Assoc UK 60:963-975

> Nipper MG, Roper DS, Williams EK, Martin ML, Van Dam LF, Mills GN (1998) Sediment toxicity and benthic communities in mildly contaminated mudflats. Environ Toxicol Chem 17:502-510

Pedersen ER, Perkins MA (1986) The use of benthic invertebrate data for evaluating impacts of urban run-off. Hydrobiologia 139:13-22

> Pressey RL, Cabeza M, Watts ME, Cowling RM, Wilson KA (2007) Conservation planning in a changing world. Trends Ecol Evol 22:583-592

> Roberts DA, Poore AGB, Johnston EL (2007) MBACI sampling of an episodic disturbance: stormwater effects on algal epifauna. Mar Environ Res 64:514-523

Roberts DA, Johnston EL, Muller S, Poore AGB (2008a) Field and laboratory simulations of storm water pulses: behavioural avoidance by marine epifauna. Environ Pollut 152: 153-162

Roberts DA, Johnston EL, Poore AGB (2008b) Contamination of marine biogenic habitats and effects upon associ- ated epifauna. Mar Pollut Bull 56:1057-1065

> Schiff K, Bay S, Diehl D (2003) Stormwater toxicity in Chollas Creek and San Diego Bay, California. Environ Monit Assess 81:119-132

> Sheppard CRC, Bellamy DJ, Sheppard ALS (1980) Study of the fauna inhabiting the holdfasts of Laminaria hyperborea (Gunn.) Fosl. along some environmental and geographic gradients. Mar Environ Res 4:25-51

Skinner L, de Peyster A, Schiff K (1999) Developmental effects of urban storm water in medaka (Oryzias latipes) and inland silverside (Menidia beryllina). Arch Environ Contam Toxicol 37:227-235

Smith SDA (1994) Impact of domestic sewage effluent versus natural background variability: an example from Jervis Bay, New South Wales. Aust J Mar Freshw Res 45: 1045-1064

Smith SDA (1996a) The effects of domestic sewage effluent on marine communities at Coffs Harbour, NSW, Australia. Mar Pollut Bull 33:309-316

Smith SDA (1996b) The macrofaunal community of Ecklonia radiata holdfasts: variation associated with sediment regime, sponge cover and depth. Aust J Ecol 21: 144-153

Smith SDA (2000) Evaluating stress in rocky shore and shallow reef habitats using the macrofauna of kelp holdfasts. J Aquat Ecosyst Stress Recov 7:259-272

Smith SDA, Rule MJ (2002) Artificial substrata in a shallow sublittoral habitat: Do they adequately represent natural habitats or the local species pool? J Exp Mar Biol Ecol 277:25-41

Smith SDA, Simpson RD (1992) Monitoring the shallow sublittoral using the fauna of kelp (Ecklonia radiata) holdfasts. Mar Pollut Bull 24:46-52

Smith SDA, Simpson RD (1995) Effects of the 'Nella Dan' oil spill on the fauna of Durvillea antarctica holdfasts. Mar Ecol Prog Ser 121:73-89

Smith SDA, Simpson RD, Cairns SC (1996) The macrofaunal community of Ecklonia radiata holdfasts: description of the faunal assemblage and variation associated with differences in holdfast volume. Aust J Ecol 21:81-95

Sokal RR, Rohlf FJ (1995) Biometry: the principles and practice of statistics in biological research, 3rd edn. W. H. Freeman, New York, NY

Underwood AJ (1988) Design and analysis of field experiments on competitive interactions affecting behaviour of intertidal animals. In: Chelazzi $G$, Vannini $M$ (eds) Behavioural adaptation to intertidal life. NATO Asi Series A, Life Sciences, Vol 151. Plenum Press, New York, NY, p 153-172

> Underwood AJ (1989) The analysis of stress in natural populations. Biol J Linn Soc 37:51-78

> Underwood AJ (1994) On beyond BACI: sampling designs that might reliably detect environmental disturbances. Ecol Appl 4:3-15

Underwood AJ (1997) Experiments in ecology: their logical design and interpretation using analysis of variance. Cambridge University Press, Cambridge

> Underwood AJ, Chapman MG (2006) Early development of subtidal macrofaunal assemblages: relationships to period and timing of colonization. J Exp Mar Biol Ecol 330: 221-233

Washburn L, McClure KA, Jones BH, Bay SM (2003) Spatial scales and evolution of stormwater plumes in Santa Monica Bay. Mar Environ Res 56:103-125

Submitted: January 18, 2011; Accepted: July 19, 2011

Proofs received from author(s): October 10, 2011 